\title{
Best proximity results for Suzuki and convex type contractions
}

\author{
Nawab Hussain ${ }^{1}$, Masoomeh Hezarjaribi ${ }^{2}$, MA Kutbi $^{{ }^{*}}$ and Peyman Salimi ${ }^{3}$
}

\section{${ }^{*}$ Correspondence:}

mkutbi@yahoo.com

${ }^{1}$ Department of Mathematics, King

Abdulaziz University, P.O. Box 80203

Jeddah, 21589, Saudi Arabia

Full list of author information is

available at the end of the article

\begin{abstract}
The aim of the paper is to introduce new Suzuki and convex type contractions and prove new best proximity results for these contractions in the setting of a metric space. As applications, we deduce similar results for such type of contractions in partially ordered metric spaces and derive new Suzuki type fixed point results. An illustrative example is provided here to highlight our findings.
\end{abstract}

Keywords: best proximity point; proximal $\alpha$-admissible mapping; Suzuki type proximal contractions

\section{Introduction and preliminaries}

The background literature on best proximity theory and associated fixed point theory in (ordered) metric spaces, Banach spaces and fuzzy metric spaces is very abundant in the literature; see, for instance, [1-6] and references therein.

For any two nonempty sets $\mathrm{A}$ and $\mathrm{B}$ in a metric space $(X, d)$, the point $p \in A$ is called a best proximity point of the mapping $T: A \rightarrow B$ if $d(p, T p)=d(A, B)$, where $d(A, B)=$ $\inf \{d(x, y): x \in A, y \in B\}$. We shall denote the set of best proximity points of $T$ by $\operatorname{Bpp}(T)$. For more details, we refer the reader to [7-11] and [4-6, 12-31].

We define

$$
\begin{aligned}
& A_{0}=\{p \in A: d(p, q)=d(A, B) \text { for some } q \in B\}, \\
& B_{0}=\{q \in B: d(p, q)=d(A, B) \text { for some } p \in A\} .
\end{aligned}
$$

Definition 1.1 [20] For nonempty subsets $A, B$ of metric space $(X, d)$ with $A_{0} \neq \emptyset$, we say the pair $(A, B)$ satisfy

(a) the $P$-property if

$$
\left\{\begin{array}{l}
d\left(x_{1}, y_{1}\right)=d(A, B), \\
d\left(x_{2}, y_{2}\right)=d(A, B),
\end{array} \quad \Longrightarrow \quad d\left(x_{1}, x_{2}\right)=d\left(y_{1}, y_{2}\right)\right.
$$

for all $x_{1}, x_{2} \in A$ and $y_{1}, y_{2} \in B$,

(b) the weak $P$-property $[22,26]$ if for any $x_{1}, x_{2} \in A_{0}$ and $y_{1}, y_{2} \in B_{0}$,

$$
d\left(x_{1}, y_{1}\right)=d(A, B) \quad \text { and } \quad d\left(x_{2}, y_{2}\right)=d(A, B) \quad \Rightarrow \quad d\left(x_{1}, x_{2}\right) \leq d\left(y_{1}, y_{2}\right) .
$$

(c) 2016 Hussain et al. This article is distributed under the terms of the Creative Commons Attribution 4.0 International License (http://creativecommons.org/licenses/by/4.0/), which permits unrestricted use, distribution, and reproduction in any medium, provided you give appropriate credit to the original author(s) and the source, provide a link to the Creative Commons license, and indicate if changes were made. 
We shall use $\Psi=\left\{\psi:[0,+\infty) \rightarrow[0,+\infty): \sum_{n=1}^{\infty} \psi^{n}(t)<+\infty\right.$ for all $\left.t>0\right\}$, where $\psi$ is nondecreasing function.

Now we introduce new concepts of proximal mappings, for more details see [5].

Definition 1.2 If $\alpha: A \times A \rightarrow[-\infty, \infty)$, then $T: A \rightarrow B$ is called proximal $\alpha^{+}$-admissible if

$$
\left\{\begin{array}{l}
\alpha\left(x_{1}, x_{2}\right) \geq 0, \\
d\left(u_{1}, T x_{1}\right)=d(A, B), \quad \Longrightarrow \quad \alpha\left(u_{1}, u_{2}\right) \geq 0 \\
d\left(u_{2}, T x_{2}\right)=d(A, B),
\end{array}\right.
$$

for all $x_{1}, x_{2}, u_{1}, u_{2} \in A$.

Definition 1.3 The mapping $T: A \rightarrow B$ is called a Suzuki type $\alpha^{+} \psi$-proximal contraction, if

$$
\frac{1}{2} d^{*}(x, T x) \leq d(x, y) \quad \Rightarrow \quad \alpha(x, y)+d(T x, T y) \leq \psi(M(x, y))
$$

for all $x, y \in A$, where $d^{*}(x, T x)=d(x, T x)-d(A, B), \alpha: A \times A \rightarrow[-\infty, \infty), \psi \in \Psi$, and

$$
M(x, y)=\max \left\{d(x, y), \frac{d(x, T x)+d(y, T y)}{2}-d(A, B), \frac{d(x, T y)+d(y, T x)}{2}-d(A, B)\right\}
$$

In this manuscript, we propose new types of Suzuki and convex proximal maps to prove best proximity results. We also derive similar results in ordered metric spaces. Several interesting consequences of our obtained results are presented here.

\section{Suzuki type $\alpha^{+} \psi$-proximal maps}

Now we prove our first main result.

Theorem 2.1 Suppose $A$ and $B$ are nonempty closed subsets of a complete metric space $X$ with $A_{0} \neq \emptyset$. Let $T: A \rightarrow B$ satisfy (1.3) together with the following assertions:

(i) $T\left(A_{0}\right) \subseteq B_{0}$ and $(A, B)$ satisfies the weak P-property,

(ii) $T$ is proximal $\alpha^{+}$-admissible,

(iii) there exist $x_{0}, x_{1} \in A_{0}$ such that

$$
d\left(x_{1}, T x_{0}\right)=d(A, B) \text { and } \alpha\left(x_{0}, x_{1}\right) \geq 0,
$$

(iv) $T$ is continuous, or

(v) $A$ is $\alpha$-regular, that is, if $\left\{x_{n}\right\}$ is a sequence in $A$ such that $\alpha\left(x_{n}, x_{n+1}\right) \geq 0$ and $x_{n} \rightarrow x \in A$ as $n \rightarrow \infty$, then $\alpha\left(x_{n}, x\right) \geq 0$ for all $n \in \mathbb{N}$.

Then $\operatorname{Bpp}(T)$ is nonempty.

Proof Since $T\left(A_{0}\right) \subseteq B_{0}$, we have $x_{2} \in A_{0}$ such that

$$
d\left(x_{2}, T x_{1}\right)=d(A, B) .
$$


As $T$ satisfies (iii) and is proximal $\alpha^{+}$-admissible, we obtain $\alpha\left(x_{1}, x_{2}\right) \geq 0$. That is,

$$
d\left(x_{2}, T x_{1}\right)=d(A, B), \quad \alpha\left(x_{1}, x_{2}\right) \geq 0
$$

Again, since $T\left(A_{0}\right) \subseteq B_{0}$, there exists $x_{3} \in A_{0}$ such that

$$
d\left(x_{3}, T x_{2}\right)=d(A, B)
$$

Thus we have

$$
d\left(x_{2}, T x_{1}\right)=d(A, B), \quad d\left(x_{3}, T x_{2}\right)=d(A, B), \quad \alpha\left(x_{1}, x_{2}\right) \geq 0
$$

Again since $T$ is proximal $\alpha^{+}$-admissible, so $\alpha\left(x_{2}, x_{3}\right) \geq 0$. Hence,

$$
d\left(x_{3}, T x_{2}\right)=d(A, B), \quad \alpha\left(x_{2}, x_{3}\right) \geq 0 .
$$

We continue this process, to get

$$
d\left(x_{n+1}, T x_{n}\right)=d(A, B), \quad \alpha\left(x_{n+1}, x_{n}\right) \geq 0 \quad \text { for all } n \in \mathbb{N} \cup\{0\} .
$$

By using the above observations we can write

$$
\begin{aligned}
\frac{1}{2} d^{*}\left(x_{n-1}, T x_{n-1}\right) & =\frac{1}{2}\left[d\left(x_{n-1}, T x_{n-1}\right)-d(A, B)\right] \\
& \leq \frac{1}{2}\left[d\left(x_{n-1}, x_{n}\right)+d\left(x_{n}, T x_{n-1}\right)-d(A, B)\right] \\
& =\frac{1}{2} d\left(x_{n-1}, x_{n}\right) \\
& \leq d\left(x_{n}, x_{n-1}\right) .
\end{aligned}
$$

That is,

$$
\frac{1}{2} d^{*}\left(x_{n-1}, T x_{n-1}\right) \leq d\left(x_{n}, x_{n-1}\right)
$$

Now from (1.3) we get

$$
d\left(T x_{n-1}, T x_{n}\right) \leq \alpha\left(x_{n-1}, x_{n}\right)+d\left(T x_{n-1}, T x_{n}\right) \leq \psi\left(M\left(x_{n-1}, x_{n}\right)\right) .
$$

By a simple calculation we obtain (see for details $[2,5]$ ),

$$
\begin{aligned}
M\left(x_{n-1}, x_{n}\right)= & \max \left\{d\left(x_{n-1}, x_{n}\right), \frac{d\left(x_{n-1}, T x_{n-1}\right)+d\left(x_{n}, T x_{n}\right)}{2}-d(A, B)\right. \\
& \left.\frac{d\left(x_{n-1}, T x_{n}\right)+d\left(x_{n}, T x_{n-1}\right)}{2}-d(A, B)\right\} \\
\leq & \max \left\{d\left(x_{n-1}, x_{n}\right), d\left(x_{n}, x_{n+1}\right)\right\}
\end{aligned}
$$


By the weak $P$-property and (2.1) one obtains

$$
d\left(x_{n}, x_{n+1}\right) \leq d\left(T x_{n-1}, T x_{n}\right) \quad \text { for all } n \in \mathbb{N}
$$

Equations (2.2) and (2.3) imply that

$$
d\left(x_{n}, x_{n+1}\right) \leq \psi\left(M\left(x_{n-1}, x_{n}\right)\right) \leq \psi\left(\max \left\{d\left(x_{n-1}, x_{n}\right), d\left(x_{n}, x_{n+1}\right)\right\}\right) \quad \text { for all } n \in \mathbb{N}
$$

If $x_{n_{0}}=x_{n_{0}+1}$ for some $n_{0} \in \mathbb{N}$, from (2.1) one obtains

$$
d\left(x_{n_{0}}, T x_{n_{0}}\right)=d\left(x_{n_{0}+1}, T x_{n_{0}}\right)=d(A, B)
$$

that is, $x_{n_{0}} \in \operatorname{Bpp}(T)$. Thus, we suppose that

$$
d\left(x_{n+1}, x_{n}\right)>0 \quad \text { for all } n \in \mathbb{N} \cup\{0\} .
$$

If, $\max \left\{d\left(x_{n-1}, x_{n}\right), d\left(x_{n}, x_{n+1}\right)\right\}=d\left(x_{n}, x_{n+1}\right)$, then (2.4) implies

$$
d\left(x_{n}, x_{n+1}\right) \leq \psi\left(d\left(x_{n}, x_{n+1}\right)\right)<d\left(x_{n}, x_{n+1}\right)
$$

which is a contradiction. Thus,

$$
d\left(x_{n}, x_{n+1}\right) \leq \psi\left(d\left(x_{n-1}, x_{n}\right)\right)<d\left(x_{n-1}, x_{n}\right) \quad \text { for all } n \in \mathbb{N} \text {. }
$$

Applying the monotonicity of $\psi$, by induction, it follows from (2.6),

$$
d\left(x_{n}, x_{n+1}\right) \leq \psi^{n}\left(d\left(x_{1}, x_{0}\right)\right) \quad \text { for all } n \in \mathbb{N} \cup\{0\}
$$

Suppose $\epsilon$ is any positive real number. Then there exists $N \in \mathbb{N}$ such that

$$
\sum_{n \geq N} \psi^{n}\left(d\left(x_{0}, x_{1}\right)\right)<\epsilon \quad \text { for all } n \in \mathbb{N} \text {. }
$$

If $m, n \in \mathbb{N}$ with $m>n \geq N$. We apply the triangle inequality to get

$$
d\left(x_{n}, x_{m}\right) \leq \sum_{k=n}^{m-1} d\left(x_{k}, x_{k+1}\right) \leq \sum_{k=n}^{m-1} \psi^{k}\left(d\left(x_{0}, x_{1}\right)\right)<\sum_{n \geq N} \psi^{n}\left(d\left(x_{0}, x_{1}\right)\right)<\epsilon
$$

Consequently $\lim _{m, n, \rightarrow+\infty} d\left(x_{n}, x_{m}\right)=0$, which implies $\left\{x_{n}\right\}$ is Cauchy sequence. By completeness of $X, x_{n} \rightarrow z \in X$. If (iv) holds, then $T x_{n} \rightarrow T z$ as $n \rightarrow \infty$ and

$$
d(A, B)=\lim _{n \rightarrow \infty} d\left(x_{n+1}, T x_{n}\right)=d(z, T z)
$$

as required. Next, assume that (v) holds. Then $\alpha\left(x_{n}, z\right) \geq 0$.

If the following inequalities hold:

$$
\frac{1}{2} d^{*}\left(x_{n}, T x_{n}\right)>d\left(x_{n}, z\right) \text { and } \frac{1}{2} d^{*}\left(x_{n+1}, T x_{n+1}\right)>d\left(x_{n+1}, z\right) \text {, }
$$


for some $n \in \mathbb{N}$, then by using (2.6) and definition of $d^{*}$, we obtain the following contradiction:

$$
\begin{aligned}
d\left(x_{n}, x_{n+1}\right) & \leq d\left(x_{n}, z\right)+d\left(x_{n+1}, z\right) \\
& <\frac{1}{2}\left[d^{*}\left(x_{n}, T x_{n}\right)+d^{*}\left(x_{n+1}, T x_{n+1}\right)\right] \\
& \leq \frac{1}{2}\left[d\left(x_{n}, T x_{n}\right)+d\left(x_{n+1}, T x_{n+1}\right)-2 d(A, B)\right] \\
& =d\left(x_{n}, x_{n+1}\right) .
\end{aligned}
$$

Consequently, for any $n \in \mathbb{N}$, either

$$
\frac{1}{2} d^{*}\left(x_{n}, T x_{n}\right) \leq d\left(x_{n}, z\right) \quad \text { or } \quad \frac{1}{2} d^{*}\left(x_{n+1}, T x_{n+1}\right) \leq d\left(x_{n+1}, z\right)
$$

holds. Thus, we may pick a subsequence $\left\{x_{n_{k}}\right\}$ of $\left\{x_{n}\right\}$ such that

$$
\frac{1}{2} d^{*}\left(x_{n_{k}}, T x_{n_{k}}\right) \leq d\left(x_{n_{k}}, z\right) \quad \text { and } \quad \alpha\left(x_{n_{k}}, x_{n_{k}+1}\right) \geq 0
$$

for all $k \in \mathbb{N}$. By (1.3) we get

$$
d\left(T x_{n_{k}}, T z\right) \leq \psi\left(M\left(x_{n_{k}}, z\right)\right)
$$

Notice that

$$
\begin{aligned}
M\left(x_{n_{k}}, z\right)= & \max \left\{d\left(x_{n_{k}}, z\right), \frac{d\left(x_{n_{k}}, T x_{n_{k}}\right)+d(z, T z)}{2}-d(A, B),\right. \\
& \left.\frac{d\left(x_{n_{k}}, T z\right)+d\left(z, T x_{n_{k}}\right)}{2}-d(A, B)\right\} \\
\leq & \max \left\{d\left(x_{n_{k}}, z\right), \frac{d\left(x_{n_{k}}, x_{n_{k}+1}\right)+d\left(x_{n_{k}+1}, T x_{n_{k}}\right)+d(z, T z)}{2}-d(A, B),\right. \\
& \left.\frac{d\left(x_{n_{k}}, z\right)+d(z, T z)+d\left(z, x_{n_{k}+1}\right)+d\left(x_{n_{k}+1}, T x_{n_{k}}\right)}{2}-d(A, B)\right\} \\
= & \max \left\{d\left(x_{n_{k}}, z\right), \frac{d\left(x_{n_{k}}, x_{n_{k}+1}\right)+d(A, B)+d(z, T z)}{2}-d(A, B),\right. \\
& \left.\frac{d\left(x_{n_{k}}, z\right)+d(z, T z)+d\left(z, x_{n_{k}+1}\right)+d(A, B)}{2}-d(A, B)\right\},
\end{aligned}
$$

which implies

$$
\lim _{k \rightarrow \infty} M\left(x_{n_{k}}, z\right) \leq \frac{d(z, T z)-d(A, B)}{2} .
$$

Further,

$$
\begin{aligned}
d(z, T z) & \leq d\left(z, x_{n_{k}+1}\right)+d\left(x_{n_{k}+1}, T x_{n_{k}}\right)+d\left(T x_{n_{k}}, T z\right) \\
& \leq d\left(z, x_{n_{k}+1}\right)+d(A, B)+d\left(T x_{n_{k}}, T z\right),
\end{aligned}
$$


which gives

$$
d(z, T z)-d\left(z, x_{n_{k}+1}\right)-d(A, B) \leq d\left(T x_{n_{k}}, T z\right) .
$$

As $k \rightarrow \infty$ in (2.9) we deduce

$$
d(z, T z)-d(A, B) \leq \lim _{k \rightarrow \infty} d\left(T x_{n_{k}}, T z\right)
$$

Therefore from (2.7), (2.8), and (2.10)

$$
\begin{aligned}
d(z, T z)-d(A, B) & \leq \lim _{k \rightarrow \infty} d\left(T x_{n_{k}}, T z\right) \\
& \leq \psi\left(\lim _{k \rightarrow \infty} M\left(x_{n_{k}}, z\right)\right) \leq \psi\left(\frac{d(z, T z)-d(A, B)}{2}\right)
\end{aligned}
$$

Now, if $d(z, T z)-d(A, B)>0$, then we get

$$
d(z, T z)-d(A, B) \leq \psi\left(\frac{d(z, T z)-d(A, B)}{2}\right)<\frac{d(z, T z)-d(A, B)}{2}
$$

a contradiction. Hence, $d(z, T z)=d(A, B)$ as desired.

Example 2.1 Suppose $X=\mathbb{R}^{2}$ is equipped with the metric

$$
d\left(\left(p_{1}, p_{2}\right),\left(q_{1}, q_{2}\right)\right)=\left|p_{1}-q_{1}\right|+\left|p_{2}-q_{2}\right|,
$$

for all $\left(p_{1}, p_{2}\right),\left(q_{1}, q_{2}\right) \in X$. Let $A_{1}=\left\{(p, q) \mid p=1,0 \leq q \leq \frac{1}{2}\right\}, A_{2}=\{(p, q) \mid p=4, q \geq 5\}, A_{3}=$ $\{(p, q) p=5, q \geq 4\}, A_{4}=\{(p, q) \mid p=3, q \geq 3\}$ and $A=A_{1} \cup A_{2} \cup A_{3} \cup A_{4}$. Further define $B_{1}=\left\{(p, q) \mid p=\frac{1}{2}, \frac{1}{2} \leq q \leq 1\right\}, B_{2}=\{(p, q) \mid p=0, q \leq 4\}, B_{3}=\{(P, q) \mid p=4, q \leq 0\}$, and $B=$ $B_{1} \cup B_{2} \cup B_{3}$.

Note that $d(A, B)=1, A_{0}=\left\{(p, q) \mid p=1,0 \leq q \leq \frac{1}{2}\right\}$, and $B_{0}=\left\{(p, q) \mid p=\frac{1}{2}, \frac{1}{2} \leq q \leq 1\right\}$. Let, for $x_{1}=\left(1, u_{1}\right), x_{2}=\left(1, u_{2}\right) \in A_{0}$ and $y_{1}=\left(\frac{1}{2}, v_{1}\right), y_{2}=\left(\frac{1}{2}, v_{2}\right) \in B_{0}$, us have $d\left(x_{1}, y_{1}\right)=d(A, B)=$ 1 and $d\left(x_{2}, y_{2}\right)=d(A, B)=1$. Then

$$
\frac{1}{2}+\left|u_{1}-v_{1}\right|=1
$$

and

$$
\frac{1}{2}+\left|u_{2}-v_{2}\right|=1
$$

and so $\left|u_{1}-v_{1}\right|=\frac{1}{2}$ and $\left|u_{2}-v_{2}\right|=\frac{1}{2}$. Since $v_{1}, v_{2} \geq u_{1}, u_{2}$, we have $v_{1}=\frac{1}{2}+u_{1}$ and $v_{2}=\frac{1}{2}+u_{2}$. This shows that $d\left(x_{1}, x_{2}\right) \leq d\left(y_{1}, y_{2}\right)$. So $(A, B)$ satisfy the weak $P$-property. Let $T: A \rightarrow B$ be defined by

$$
T\left(p_{1}, p_{2}\right)= \begin{cases}\left(\frac{1}{2}, \frac{1}{2}\right) & \text { if } p_{1}=p_{2} \\ \left(p_{1}, 0\right) & \text { if } p_{1}<p_{2} \\ \left(0, p_{2}\right) & \text { if } p_{1}>p_{2}\end{cases}
$$

Notice that $T\left(A_{0}\right) \subseteq B_{0}$. 
Define the functions $\psi:[0,+\infty) \rightarrow[0,+\infty)$ and $\alpha: A \times A \rightarrow[-\infty, \infty)$ by

$$
\psi(t)=\frac{8}{9} t \quad \text { and } \quad \alpha(p, q)= \begin{cases}0, & \text { if } p, q \in\{(1,0),(4,5),(5,4)\} \\ -\infty, & \text { otherwise }\end{cases}
$$

Assume that $\frac{1}{2} d^{*}(p, T p) \leq d(p, q)$ and $\alpha(p, q) \geq 0$, for $p, q \in A$. Then

$$
\left\{\begin{array}{lll}
p=(1,0), & q=(4,5) & \text { or } \\
p=(1,0), & q=(5,4) & \text { or } \\
q=(1,0), & p=(4,5) & \text { or } \\
q=(1,0), & p=(5,4) .
\end{array}\right.
$$

Since $d(T p, T q)=d(T q, T p)$ and $M(p, q)=M(q, p)$ for all $p, q \in A$, we can suppose that

$$
(p, q)=((1,0),(4,5)) \quad \text { or } \quad(p, q)=((1,0),(5,4))
$$

Now, we discuss the following cases:

(i) if $(p, q)=((1,0),(4,5))$, then

$$
d(T(1,0), T(4,5))=4 \leq 7=\frac{7}{8} \cdot 8=\psi(d((1,0), d(4,5))) \leq \psi(M(p, q))
$$

(ii) if $(p, q)=((1,0),(5,4))$, then

$$
d(T(1,0), T(5,4))=4 \leq \frac{7}{8} \cdot 8=\psi(d((1,0),(5,4))) \leq \psi(M(p, q))
$$

Consequently, we have

$$
\frac{1}{2} d^{*}(p, T p) \leq d(p, q) \quad \Rightarrow \quad d(T p, T q) \leq \psi(M(p, q))
$$

Thus all the assumptions of Theorem 2.1 are satisfied and $\operatorname{Bpp}(T)=\{(1,0)\}$.

The next result can be deduced easily from Theorem 2.1 .

Theorem 2.2 Let $X, A, A_{0}$, and $B$ be as in Theorem 2.1. Assume that $T: A \rightarrow B$ satisfies the assertions (i)-(v) in Theorem 2.1 and

$$
\alpha(p, q)+d(T p, T q) \leq \psi(M(p, q))
$$

holds for all $p, q \in A$. Then $\operatorname{Bpp}(T)$ is nonempty.

If $\alpha=0$ on $A$, in Theorem 2.1, we obtain the following new result.

Corollary 2.1 Suppose $X, A, A_{0}$, and $B$ are as in Theorem 2.1 and $T: A \rightarrow B$ satisfies the following assumptions:

(i) $T\left(A_{0}\right) \subseteq B_{0}$ and $(A, B)$ satisfies the weak P-property, 
(ii) for all $p, q \in A$ with $\frac{1}{2} d^{*}(p, T p) \leq d(p, q)$ we have

$d(T p, T q) \leq \psi(M(p, q))$

Then $\operatorname{Bpp}(T)$ is nonempty.

\section{$3 \alpha^{+} \Theta$-proximal maps}

This section deals with best proximity theorems for Suzuki contractions involving the $\Theta$ function which was recently introduced by Jleli and Samet [27].

Let $\Delta_{\Theta}$ denote the set of all functions $\Theta:(0, \infty) \rightarrow[1, \infty)$ with the following conditions:

$\left(\Theta_{1}\right) \Theta$ is increasing;

$\left(\Theta_{2}\right)$ for all sequences $\left\{\alpha_{n}\right\} \subseteq(0, \infty), \lim _{n \rightarrow \infty} \alpha_{n}=0$ if and only if $\lim _{n \rightarrow \infty} \Theta\left(\alpha_{n}\right)=1$;

$\left(\Theta_{3}\right)$ there exist $0<r<1$ and $\ell \in(0, \infty]$ such that $\lim _{n \rightarrow 0^{+}} \frac{\Theta(t)-1}{t^{r}}=\ell$.

Definition 3.1 A mapping $T: A \rightarrow B$ is called a Suzuki type $\alpha^{+} \Theta$-proximal contraction, if for all $x, y \in A$ with $\frac{1}{2} d^{*}(x, T x) \leq d(x, y)$ and $d(T x, T y)>0$,

$$
\Rightarrow \quad \alpha(x, y)+\Theta(d(T x, T y)) \leq[\Theta(M(x, y))]^{k},
$$

where $\alpha: A \times A \rightarrow[-\infty, \infty), 0 \leq k<1$, and $\Theta \in \Delta_{\Theta}$.

Theorem 3.1 Assume that $X, A, A_{0}$, and $B$ are as in Theorem 2.1 and $T: A \rightarrow B$ satisfy (3.1) and the assertions (i)-(v) in Theorem 2.1. Then $\operatorname{Bpp}(T)$ is nonempty.

Proof As in the proof of Theorem 2.1, we can construct a sequence $\left\{x_{n}\right\}$ satisfying

$$
d\left(x_{n+1}, T x_{n}\right)=d(A, B), \quad \alpha\left(x_{n}, x_{n+1}\right) \geq 0, \quad n \in \mathbb{N} \cup\{0\}
$$

and

$$
\frac{1}{2} d^{*}\left(x_{n-1}, T x_{n-1}\right) \leq d\left(x_{n}, x_{n-1}\right) \quad \text { and } \quad d\left(x_{n}, x_{n-1}\right)>0 \quad \text { for all } n \in \mathbb{N} \text {. }
$$

Now (3.1) implies

$$
\Theta\left(d\left(T x_{n-1}, T x_{n}\right)\right) \leq \alpha\left(x_{n-1}, x_{n}\right)+\Theta\left(d\left(T x_{n-1}, T x_{n}\right)\right) \leq\left[\Theta\left(M\left(x_{n-1}, x_{n}\right)\right)\right]^{k}
$$

In Theorem 2.1 we obtain

$$
M\left(x_{n-1}, x_{n}\right) \leq \max \left\{d\left(x_{n-1}, x_{n}\right), d\left(x_{n}, x_{n+1}\right)\right\}
$$

and

$$
d\left(x_{n}, x_{n+1}\right) \leq d\left(T x_{n-1}, T x_{n}\right) \quad \text { for all } n \in \mathbb{N} .
$$


Therefore from (3.3) and (3.4) we get

$$
\begin{aligned}
\Theta\left(d\left(x_{n}, x_{n+1}\right)\right) & \leq \Theta\left(d\left(T x_{n-1}, T x_{n}\right)\right) \\
& \leq\left[\Theta\left(M\left(x_{n-1}, x_{n}\right)\right)\right]^{k} \\
& \leq\left[\Theta\left(\max \left\{d\left(x_{n-1}, x_{n}\right), d\left(x_{n}, x_{n+1}\right)\right\}\right)\right]^{k} \quad \text { for all } n \in \mathbb{N} .
\end{aligned}
$$

Now if $\max \left\{d\left(x_{n-1}, x_{n}\right), d\left(x_{n}, x_{n+1}\right)\right\}=d\left(x_{n}, x_{n+1}\right)$, then from (3.5) we get

$$
\Theta\left(d\left(x_{n}, x_{n+1}\right)\right) \leq\left[\Theta\left(d\left(x_{n}, x_{n+1}\right)\right)\right]^{k}<\Theta\left(d\left(x_{n}, x_{n+1}\right)\right)
$$

which is a contradiction. Hence,

$$
\Theta\left(d\left(x_{n}, x_{n+1}\right)\right) \leq\left[\Theta\left(d\left(x_{n-1}, x_{n}\right)\right)\right]^{k} \quad \text { for all } n \in \mathbb{N} .
$$

Therefore,

$$
\begin{aligned}
1 & \leq \Theta\left(d\left(x_{n}, x_{n+1}\right)\right) \leq \Theta\left(d\left(x_{n-1}, x_{n}\right)\right)^{k} \\
& \leq \Theta\left(d\left(x_{n-2}, x_{n-1}\right)\right)^{k^{2}} \leq \cdots \leq \Theta\left(d\left(x_{0}, x_{1}\right)\right)^{k^{n}} .
\end{aligned}
$$

Taking the limit as $n \rightarrow \infty$ in (3.7) we have

$$
\lim _{n \rightarrow \infty} \Theta\left(d\left(x_{n}, x_{n+1}\right)\right)=1
$$

and since $\Theta \in \Delta_{\Theta}$ we obtain

$$
\lim _{n \rightarrow \infty} d\left(x_{n}, x_{n+1}\right)=0
$$

Again since $\Theta \in \Delta_{\Theta}$, there exist $0<r<1$ and $0<\ell \leq \infty$ with

$$
\lim _{n \rightarrow \infty} \frac{\Theta\left(d\left(x_{n}, x_{n+1}\right)\right)-1}{\left[d\left(x_{n}, x_{n+1}\right)\right]^{r}}=\ell
$$

Assume that $\ell<\infty$. Let $C=\frac{\ell}{2}$. Thus there exists $n_{0} \in \mathbb{N}$ such that

$$
\left|\frac{\Theta\left(d\left(x_{n}, x_{n+1}\right)\right)-1}{\left[d\left(x_{n}, x_{n+1}\right)\right]^{r}}-\ell\right| \leq C \text { for all } n \geq n_{0},
$$

hence

$$
\frac{\Theta\left(d\left(x_{n}, x_{n+1}\right)\right)-1}{\left[d\left(x_{n}, x_{n+1}\right)\right]^{r}} \geq \ell-C=C \quad \text { for all } n \geq n_{0},
$$

and so

$$
n\left[d\left(x_{n}, x_{n+1}\right)\right]^{r} \leq n D\left[\Theta\left(d\left(x_{n}, x_{n+1}\right)\right)-1\right] \text { for all } n \geq n_{0},
$$


where $D=\frac{1}{C}$. If $\ell=\infty$, then there exists $n_{0} \in \mathbb{N}$,

$$
\frac{\Theta\left(d\left(x_{n}, x_{n+1}\right)\right)-1}{\left[d\left(x_{n}, x_{n+1}\right)\right]^{r}} \geq C \text { for all } n \geq n_{0},
$$

which implies

$$
n\left[d\left(x_{n}, x_{n+1}\right)\right]^{r} \leq n D\left[\Theta\left(d\left(x_{n}, x_{n+1}\right)\right)-1\right] \text { for all } n \geq n_{0},
$$

where $D=\frac{1}{C}$. Hence, in all cases there exist $D>0$ and $n_{0} \in \mathbb{N}$ such that

$$
n\left[d\left(x_{n}, x_{n+1}\right)\right]^{r} \leq n D\left[\Theta\left(d\left(x_{n}, x_{n+1}\right)\right)-1\right] \text { for all } n \geq n_{0} .
$$

Now (3.7) implies

$$
n\left[d\left(x_{n}, x_{n+1}\right)\right]^{r} \leq n D\left[\Theta\left(d\left(x_{0}, x_{1}\right)\right)^{k^{n}}-1\right] \text { for all } n \geq n_{0},
$$

and on letting $n \rightarrow \infty$ we obtain

$$
\lim _{n \rightarrow \infty} n\left[d\left(x_{n}, x_{n+1}\right)\right]^{r}=0 .
$$

It follows from (3.10) that there is $n_{1} \in \mathbb{N}$ with

$$
n\left[d\left(x_{n}, x_{n+1}\right)\right]^{r} \leq 1
$$

for all $n>n_{1}$. This implies

$$
d\left(x_{n}, x_{n+1}\right) \leq \frac{1}{n^{1 / r}}
$$

for all $n>n_{1}$. If $m>n>n_{1}$, then

$$
d\left(x_{n}, x_{m}\right) \leq \sum_{i=n}^{m-1} d\left(x_{i}, x_{i+1}\right) \leq \sum_{i=n}^{m-1} \frac{1}{i^{1 / r}} .
$$

Since $0<r<1, \sum_{i=n}^{\infty} \frac{1}{i^{1 / r}}$ is convergent. Thus, $d\left(x_{n}, x_{m}\right) \rightarrow 0$ as $m, n \rightarrow \infty$, which shows that $\left\{x_{n}\right\}$ is a Cauchy sequence. Thus there is $z \in X$ such that $x_{n} \rightarrow z$ as $n \rightarrow \infty$. Assume that (iv) holds. Thus $T x_{n} \rightarrow T z$ as $n \rightarrow \infty$, which implies

$$
d(A, B)=\lim _{n \rightarrow \infty} d\left(x_{n+1}, T x_{n}\right)=d(z, T z)
$$

as required. Next, assume that (v) holds. As in the proof of Theorem 2.1 we can deduce there is a subsequence $\left\{x_{n_{k}}\right\}$ of $\left\{x_{n}\right\}$ satisfying

$$
\frac{1}{2} d^{*}\left(x_{n_{k}}, T x_{n_{k}}\right) \leq d\left(x_{n_{k}}, z\right) \quad \text { and } \quad \alpha\left(x_{n_{k}}, x_{n_{k}+1}\right) \geq 0
$$

for all $k \in \mathbb{N}$. By (3.1) we get

$$
\Theta\left(d\left(T x_{n_{k}}, T z\right)\right) \leq\left[\Theta\left(M\left(x_{n_{k}}, z\right)\right)\right]^{k}<\Theta\left(M\left(x_{n_{k}}, z\right)\right),
$$


which implies

$$
d\left(T x_{n_{k}}, T z\right) \leq M\left(x_{n_{k}}, z\right) .
$$

As in Theorem 2.1 we obtain

$$
\lim _{k \rightarrow \infty} M\left(x_{n_{k}}, z\right) \leq \frac{d(z, T z)-d(A, B)}{2}
$$

and

$$
d(z, T z)-d(A, B) \leq \lim _{k \rightarrow \infty} d\left(T x_{n_{k}}, T z\right)
$$

therefore,

$$
d(z, T z)-d(A, B) \leq \frac{d(z, T z)-d(A, B)}{2},
$$

which is a contradiction when $d(z, T z)>d(A, B)$. So, $d(z, T z)=d(A, B)$, that is, $\operatorname{Bpp}(T)$ is nonempty.

Corollary 3.1 Suppose $X, A, A_{0}$, and $B$ are as in Theorem 2.1 and $T: A \rightarrow B$ satisfies the assertions (i)-(v) in Theorem 3.1. If

$$
\alpha(p, q)+\Theta(d(T p, T q)) \leq[\Theta(M(p, q))]^{k}
$$

holds for all $p, q \in A$ where $\alpha: A \times A \rightarrow[-\infty, \infty)$ and $\Theta \in \Delta_{\Theta}$, then $\operatorname{Bpp}(T)$ is nonempty.

Corollary 3.2 Suppose $X, A, A_{0}$, and $B$ are as in Theorem 2.1 and $T: A \rightarrow B$ satisfies the following assertions:

(i) $T\left(A_{0}\right) \subseteq B_{0}$ and $(A, B)$ satisfies the weak P-property;

(ii) for all $p, q \in A$ with $\frac{1}{2} d^{*}(p, T p) \leq d(p, q)$ we have

$$
\Theta(d(T p, T q)) \leq[\Theta(M(p, q))]^{k},
$$

where $\Theta \in \Delta_{\Theta}$.

Then $\operatorname{Bpp}(T)$ is nonempty.

\section{Remark 3.1}

(a) The results proved in the above sections generalize the corresponding results of Zhang et al. [26], Suzuki [22], Hussain et al. [2, 3] and many others.

(b) Several more best proximity point theorems can be obtained using more choices for the function $\Theta$, and some other concrete choices of $\alpha$ and $\psi \in \Psi$ in the results of the above sections.

\section{Best proximity results for convex type contractions}

We discuss two new and general types of proximal convex contractions and establish corresponding best proximity results (see also [8]). 
Definition 4.1 Suppose $T: A \rightarrow B$ be a mapping where $A$ and $B$ are two nonempty subsets of a metric space $X$. Then $T$ is an

(1) $\alpha^{+}$-convex proximal contractive map of the first type if, for $x, y, u, u^{*}, v \in A$,

$$
\begin{aligned}
& \alpha(x, y) \geq 0, \\
& d(u, T x)=d(A, B), \\
& d\left(u^{*}, T u\right)=d(A, B), \quad \Longrightarrow \quad d\left(u^{*}, v^{*}\right) \leq r_{1} d(u, v)+r_{2} d(x, y) \\
& d(v, T y)=d(A, B) \text {, } \\
& d\left(v^{*}, T v\right)=d(A, B)
\end{aligned}
$$

holds where $r_{1}, r_{2} \geq 0, r_{1}+r_{2}<1$

(2) $\alpha^{+}$-convex proximal contractive map of second type if for $x, y, u, u^{*}, v \in A$,

$$
\begin{aligned}
& \alpha(x, y) \geq 0, \\
& d(u, T x)=d(A, B), \\
& d\left(u^{*}, T u\right)=d(A, B), \\
& d(v, T y)=d(A, B), \\
& d\left(v^{*}, T v\right)=d(A, B) \\
& \Longrightarrow \quad d\left(u^{*}, v^{*}\right) \leq r_{1} d(x, u)+r_{2} d\left(u, u^{*}\right)+r_{3} d(y, v)+r_{4} d\left(v, v^{*}\right)
\end{aligned}
$$

holds where $r_{1}, r_{2}, r_{3}, r_{4} \geq 0, r_{1}+r_{2}+r_{3}+r_{4}<1$.

Theorem 4.1 Suppose $X, A, A_{0}$, and $B$ are as in Theorem 2.1 and $T: A \rightarrow B$ satisfy (4.1) with $T\left(A_{0}\right) \subseteq B_{0}$ and the conditions (ii)-(iv) in Theorem 2.1. Then $\operatorname{Bpp}(T)$ is nonempty. Moreover, $\operatorname{Bpp}(T)$ is a singleton if $\alpha(x, y) \geq 0$ for all $x, y \in \operatorname{Bpp}(T)$.

Proof Following the technique of the proof in Theorem 2.1, one can find a sequence $\left\{x_{n}\right\}$ such that

$$
d\left(x_{n+1}, T x_{n}\right)=d(A, B), \quad \alpha\left(x_{n}, x_{n+1}\right) \geq 0 \quad \text { for all } n \in \mathbb{N} \cup\{0\} .
$$

For

$$
x=x_{n-2}, \quad u=x_{n-1}, \quad u^{*}=x_{n}, \quad y=x_{n-1}, \quad v=x_{n} \quad \text { and } \quad v^{*}=x_{n+1},
$$

equation (4.1) implies

$$
\begin{aligned}
d\left(x_{n}, x_{n+1}\right) & \leq \alpha\left(x_{n-2}, x_{n-1}\right)+d\left(x_{n}, x_{n+1}\right) \\
& \leq r_{1} d\left(x_{n-1}, x_{n}\right)+r_{2} d\left(x_{n-2}, x_{n-1}\right) .
\end{aligned}
$$

By taking $\vartheta=d\left(x_{2}, x_{1}\right)+d\left(x_{1}, x_{0}\right)$ and $r=r_{1}+r_{2}$ we have

$$
d\left(x_{m}, x_{m+1}\right) \leq r^{l} \vartheta
$$


where $m=2 l$ or $m=2 l+1$. Let $m=2 l$. Then for $n=2 p$ with $p>2$ and $l \geq 1$ and $m<n$ we deduce

$$
\begin{aligned}
d\left(x_{m}, x_{n}\right) & \leq d\left(x_{m}, x_{m+1}\right)+d\left(x_{m+1}, x_{m+2}\right)+d\left(x_{m+2}, x_{m+3}\right)+\cdots+d\left(x_{n-1}, x_{n}\right) \\
& =d\left(x_{2} l, x_{2 l+1}\right)+d\left(x_{2 l+1}, x_{2 l+2}\right)+d\left(x_{2 l+2}, x_{2 l+3}\right)+\cdots+d\left(x_{2 p-1}, x_{2 p}\right) \\
& \leq r^{l} \vartheta+r^{l} \vartheta+r^{l+1} \vartheta+\cdots+r^{p-1} \vartheta \\
& =2 r^{l} \vartheta+2 r^{l+1} \vartheta+\cdots+2 r^{p-1} \vartheta \leq \frac{2 r^{l}}{1-r} \vartheta .
\end{aligned}
$$

Similarly, for $m=2 l$ and $n=2 p+1$ with $p \geq 1$ and $l \geq 1$ and $m<n$ we get

$$
d\left(x_{m}, x_{n}\right) \leq \frac{2 r^{l}}{1-r} \vartheta
$$

Now, assume that $m=2 l+1$. Then for $n=2 p$ with $p \geq 2$ and $l \geq 1$ and $m<n$ we have

$$
\begin{aligned}
d\left(x_{m}, x_{n}\right) & \leq d\left(x_{m}, x_{m+1}\right)+d\left(x_{m+1}, x_{m+2}\right)+d\left(x_{m+2}, x_{m+3}\right)+\cdots+d\left(x_{n-1}, x_{n}\right) \\
& =d\left(x_{2} l, x_{2 l+1}\right)+d\left(x_{2 l+1}, x_{2 l+2}\right)+d\left(x_{2 l+2}, x_{2 l+3}\right)+\cdots+d\left(x_{2 p-1}, x_{2 p}\right) \\
& \leq r^{l} \vartheta+r^{l+l} \vartheta+r^{l+1} \vartheta+\cdots+r^{p} \vartheta \\
& \leq 2 r^{l} \vartheta+2 r^{l+1} \vartheta+\cdots+2 r^{p} \vartheta \leq \frac{2 r^{l}}{1-r} \vartheta .
\end{aligned}
$$

Similarly, for $m=2 l+1$ and $n=2 p+1$ with $p \geq 1$ and $l \geq 1$ and $m<n$ we deduce

$$
d\left(x_{m}, x_{n}\right) \leq \frac{2 r^{l}}{1-r} \vartheta
$$

Hence, for all $m, n \in \mathbb{N}$ with $m<n$ we have

$$
d\left(x_{m}, x_{n}\right) \leq \frac{2 r^{l}}{1-r} \vartheta
$$

which letting $l \rightarrow \infty$ implies $d\left(x_{m}, x_{n}\right) \rightarrow 0$. That is, $\left\{x_{n}\right\}$ is a Cauchy sequence and hence there is $z \in X$ such that $x_{n} \rightarrow z$ as $n \rightarrow \infty$. Continuity of $T$ implies $T x_{n} \rightarrow T z$ as $n \rightarrow \infty$. Hence,

$$
d(A, B)=\lim _{n \rightarrow \infty} d\left(x_{n+1}, T x_{n}\right)=d(z, T z) .
$$

Let $w, z \in \operatorname{Bpp}(T)$ with $w \neq z$. Then $\alpha(w, z) \geq 0$. Now with

$$
w=x=u=u^{*}, \quad z=y=v=v^{*}
$$

(4.1) implies

$$
d(w, z) \leq \alpha(w, z)+d(w, z) \leq r_{1} d(w, z)+r_{2} d(w, z)
$$

which is a contradiction and hence $d(w, z)=0$. i.e., $w=z$. Thus $\operatorname{Bpp}(T)$ is a singleton.

By taking, $\alpha(x, y)=0$, in the above theorem we deduce the following result. 
Corollary 4.1 Suppose $X, A, A_{0}$, and $B$ are as in Theorem 2.1 and $T: A \rightarrow B$ is a continuous convex proximal contractive mapping of the first type satisfying $T\left(A_{0}\right) \subseteq B_{0}$. Then $\mathrm{Bpp}(T)$ is nonempty.

Theorem 4.2 Suppose $X, A, A_{0}$, and $B$ are as in Theorem 2.1 and $T: A \rightarrow B$ is an $\alpha^{+}$convex proximal contractive map of second type with $T\left(A_{0}\right) \subseteq B_{0}$ and satisfying conditions (ii)-(iv) in Theorem 2.1. Then $\mathrm{Bpp}(T)$ is nonempty. Moreover, $\mathrm{Bpp}(T)$ is a singleton if $\alpha(x, y) \geq 0$ for all $x, y \in \mathrm{Bpp}(T)$.

Proof As in Theorem 2.1, one may find a sequence $\left\{x_{n}\right\}$ such that

$$
d\left(x_{n+1}, T x_{n}\right)=d(A, B), \quad \alpha\left(x_{n}, x_{n+1}\right) \geq 0 \quad \text { for all } n \in \mathbb{N} \cup 0 .
$$

For

$$
x=x_{n-2}, \quad u=x_{n-1}, \quad u^{*}=x_{n}, \quad y=x_{n-1}, \quad v=x_{n} \quad \text { and } \quad v^{*}=x_{n+1}
$$

with $r=r_{1}+r_{2}+r_{3}, \eta=1-r_{4}$, and $\vartheta=d\left(x_{2}, x_{1}\right)+d\left(x_{1}, x_{0}\right),(4.2)$ implies

$$
\begin{aligned}
d\left(x_{n}, x_{n+1}\right) & \leq \alpha\left(x_{n-2}, x_{n-1}\right)+d\left(x_{n}, x_{n+1}\right) \\
& \leq r_{1} d\left(x_{n-2}, x_{n-1}\right)+r_{2} d\left(x_{n-1}, x_{n}\right)+r_{3} d\left(x_{n-1}, x_{n}\right)+r_{4} d\left(x_{n}, x_{n+1}\right) .
\end{aligned}
$$

Now if $n=2$, then

$$
\begin{aligned}
d\left(x_{2}, x_{3}\right) & \leq r_{1} d\left(x_{0}, x_{1}\right)+r_{2} d\left(x_{1}, x_{2}\right)+r_{3} d\left(x_{1}, x_{2}\right)+r_{4} d\left(x_{2}, x_{3}\right) \\
& \leq r \vartheta+r_{4} d\left(x_{2}, x_{3}\right),
\end{aligned}
$$

which implies $\left(1-r_{4}\right) d\left(x_{2}, x_{3}\right) \leq r \vartheta$. That is, $d\left(x_{2}, x_{3}\right) \leq \frac{r}{\eta} \vartheta$. Again by taking $n=3$ in (4.5) we get

$$
\begin{aligned}
d\left(x_{3}, x_{4}\right) & \leq r_{1} d\left(x_{1}, x_{2}\right)+r_{2} d\left(x_{2}, x_{3}\right)+r_{3} d\left(x_{2}, x_{3}\right)+r_{4} d\left(x_{3}, x_{4}\right) \\
& \leq r \vartheta+r_{4} d\left(x_{3}, x_{4}\right),
\end{aligned}
$$

which implies $d\left(x_{3}, x_{4}\right) \leq \frac{r}{\eta} \vartheta$. Similarly, $d\left(x_{4}, x_{5}\right) \leq\left(\frac{r}{\eta}\right)^{2} \vartheta$ and $d\left(x_{5}, x_{6}\right) \leq\left(\frac{r}{\eta}\right)^{2} \vartheta$. By continuing this process, we get $d\left(x_{m}, x_{m+1}\right) \leq\left(\frac{r}{\eta}\right)^{l} \vartheta$ when $m=2 l$ or $m=2 l+1$. Let $m=2 l$. Then for $n=2 p$ with $p>2$ and $l \geq 1$ and $m<n$ we deduce

$$
\begin{aligned}
d\left(x_{m}, x_{n}\right) & \leq d\left(x_{m}, x_{m+1}\right)+d\left(x_{m+1}, x_{m+2}\right)+d\left(x_{m+2}, x_{m+3}\right)+\cdots+d\left(x_{n-1}, x_{n}\right) \\
& =d\left(x_{2 l}, x_{2 l+1}\right)+d\left(x_{2 l+1}, x_{2 l+2}\right)+d\left(x_{2 l+2}, x_{2 l+3}\right)+\cdots+d\left(x_{2 p-1}, x_{2 p}\right) \\
& \leq\left(\frac{r}{\eta}\right)^{l} \vartheta+\left(\frac{r}{\eta}\right)^{l} \vartheta+\left(\frac{r}{\eta}\right)^{l+1} \vartheta+\cdots+\left(\frac{r}{\eta}\right)^{p-1} \vartheta \\
& =2\left(\frac{r}{\eta}\right)^{l} \vartheta+2\left(\frac{r}{\eta}\right)^{l+1} \vartheta+\cdots+2\left(\frac{r}{\eta}\right)^{p-1} \vartheta \leq \frac{2\left(\frac{r}{\eta}\right)^{l}}{1-\left(\frac{r}{\eta}\right)} \vartheta .
\end{aligned}
$$


Similarly, for $m=2 l$ and $n=2 p+1$ with $p \geq 1$ and $l \geq 1$ and $m<n$ we get

$$
d\left(x_{m}, x_{n}\right) \leq \frac{2\left(\frac{r}{\eta}\right)^{l}}{1-\left(\frac{r}{\eta}\right)} \vartheta .
$$

Now, assume that $m=2 l+1$. Then for $n=2 p$ with $p \geq 2$ and $l \geq 1$ and $m<n$ we have

$$
\begin{aligned}
d\left(x_{m}, x_{n}\right) & \leq d\left(x_{m}, x_{m+1}\right)+d\left(x_{m+1}, x_{m+2}\right)+d\left(x_{m+2}, x_{m+3}\right)+\cdots+d\left(x_{n-1}, x_{n}\right) \\
& =d\left(x_{2} l, x_{2 l+1}\right)+d\left(x_{2 l+1}, x_{2 l+2}\right)+d\left(x_{2 l+2}, x_{2 l+3}\right)+\cdots+d\left(x_{2 p-1}, x_{2 p}\right) \\
& \leq\left(\frac{r}{\eta}\right)^{l} \vartheta+\left(\frac{r}{\eta}\right)^{l+l} \vartheta+\left(\frac{r}{\eta}\right)^{l+1} \vartheta+\cdots+\left(\frac{r}{\eta}\right)^{p} \vartheta \\
& \leq 2\left(\frac{r}{\eta}\right)^{l} \vartheta+2\left(\frac{r}{\eta}\right)^{l+1} \vartheta+\cdots+2\left(\frac{r}{\eta}\right)^{p} \vartheta \leq \frac{2\left(\frac{r}{\eta}\right)^{l}}{1-\left(\frac{r}{\eta}\right)} \vartheta .
\end{aligned}
$$

Similarly, for $m=2 l+1$ and $n=2 p+1$ with $p \geq 1$ and $l \geq 1$ and $m<n$ we deduce

$$
d\left(x_{m}, x_{n}\right) \leq \frac{2\left(\frac{r}{\eta}\right)^{l}}{1-\left(\frac{r}{\eta}\right)} \vartheta
$$

Hence, for all $m, n \in \mathbb{N}$ with $m<n$ we have

$$
d\left(x_{m}, x_{n}\right) \leq \frac{2\left(\frac{r}{\eta}\right)^{l}}{1-\left(\frac{r}{\eta}\right)} \vartheta .
$$

Letting $l \rightarrow \infty$, we get $d\left(x_{m}, x_{n}\right) \rightarrow 0$. That is, $\left\{x_{n}\right\}$ is a Cauchy sequence and so there is $z \in X$ such that $x_{n} \rightarrow z$ as $n \rightarrow \infty$. BY continuity of $T, T x_{n} \rightarrow T z$ as $n \rightarrow \infty$. Hence,

$$
d(A, B)=\lim _{n \rightarrow \infty} d\left(x_{n+1}, T x_{n}\right)=d(z, T z)
$$

The proof that $\operatorname{Bpp}(T)$ is a singleton is similar to the above theorem and so is omitted.

By taking, $\alpha(x, y)=0$, in the above theorem, we deduce the following result.

Corollary 4.2 Suppose $X, A, A_{0}$, and $B$ are as in Theorem 2.1 and $T: A \rightarrow B$ is a continuous convex proximal contractive mapping of the second type satisfying $T\left(A_{0}\right) \subseteq B_{0}$. Then $\operatorname{Bpp}(T)$ is a singleton.

\section{Results in partially ordered sets}

In this section, we deduce best proximity theorems for Suzuki and convex proximal maps in partially ordered sets. 
Definition 5.1 [18] Let $(X, d, \preceq)$ be a partially ordered metric space. A map $T: A \rightarrow B$ is called proximally order-preserving if, for all $x_{1}, x_{2}, u_{1}, u_{2} \in A$,

$$
\left\{\begin{array}{l}
x_{1} \preceq x_{2}, \\
d\left(u_{1}, T x_{1}\right)=d(A, B), \\
d\left(u_{2}, T x_{2}\right)=d(A, B) .
\end{array} \quad \Longrightarrow \quad u_{1} \preceq u_{2} .\right.
$$

Definition 5.2 A mapping $T: A \rightarrow B$ is said to be Suzuki type ordered $\psi$-proximal contraction, if for $x, y \in A$

$$
\frac{1}{2} d^{*}(x, T x) \leq d(x, y) \quad \text { and } \quad x \preceq y \quad \Rightarrow \quad d(T x, T y) \leq \psi(M(x, y))
$$

Similarly, we can define order versions of other maps discussed in above sections.

Theorem 5.1 Let $A$ and $B$ be nonempty closed subsets of a complete partially ordered metric space $(X, d, \preceq)$ such that $A_{0}$ is nonempty and $T: A \rightarrow B$ be a Suzuki type ordered $\psi$ proximal map satisfying the following assertions:

(i) $T\left(A_{0}\right) \subseteq B_{0}$ and $(A, B)$ satisfies the weak P-property,

(ii) $T$ is proximally ordered-preserving,

(iii) there are $x_{0}$ and $x_{1}$ in $A_{0}$ such that

$$
d\left(x_{1}, T x_{0}\right)=d(A, B) \quad \text { and } \quad x_{0} \preceq x_{1},
$$

(iv) $T$ is continuous, or

(v) if $\left\{x_{n}\right\}$ is a increasing sequence in $A$ with $x_{n} \rightarrow x \in A$ as $n \rightarrow \infty$, then $x_{n} \preceq x$ for all $n \in \mathbb{N}$.

Then $\operatorname{Bpp}(T)$ is nonempty.

Proof Define $\alpha: A \times A \rightarrow[-\infty,+\infty)$ by

$$
\alpha(x, y)= \begin{cases}0, & \text { if } x \preceq y \\ -\infty, & \text { otherwise }\end{cases}
$$

$T$ is proximal $\alpha^{+}$-admissible mapping as follows.

$$
\left\{\begin{array}{l}
\alpha(x, y) \geq 0 \\
d(u, T x)=d(A, B) \\
d(v, T y)=d(A, B)
\end{array}\right.
$$

implies

$$
\left\{\begin{array}{l}
x \preceq y, \\
d(u, T x)=d(A, B), \\
d(v, T y)=d(A, B) .
\end{array}\right.
$$


Since $T$ is proximally ordered-preserving, $u \preceq v$, that is, $\alpha(u, v) \geq 0$. Further, by (ii) we have

$$
d\left(x_{1}, T x_{0}\right)=d(A, B) \quad \text { and } \quad \alpha\left(x_{0}, x_{1}\right) \geq 0
$$

Note that, if $x \preceq y$, then $\alpha(x, y)=0$ and otherwise, $\alpha(x, y)=-\infty$. Since $T$ is a Suzuki type ordered $\psi$-proximal map, we have the following inequality:

$$
\frac{1}{2} d^{*}(x, T x) \leq d(x, y), \quad \alpha(x, y) \geq 0 \quad \Rightarrow \quad \alpha(x, y)+d(T x, T y) \leq \psi(M(x, y)) .
$$

Further, let $\left\{x_{n}\right\}$ be a sequence, such that $\alpha\left(x_{n}, x_{n+1}\right) \geq 0$ for all $n \in \mathbb{N} \cup\{0\}$ with $x_{n} \rightarrow x$ as $n \rightarrow \infty$, then $x_{n} \preceq x_{n+1}$ for all $n \in \mathbb{N} \cup\{0\}$ with $x_{n} \rightarrow x$ as $n \rightarrow \infty$. That is, $\left\{x_{n}\right\}$ is an increasing sequence, with $x_{n} \rightarrow x$ as $n \rightarrow \infty$. So from (v) we have $x_{n} \preceq x$ for all $n \in \mathbb{N} \cup\{0\}$. That is, $\alpha\left(x_{n}, x_{n}\right) \geq 0$ for all $n \in \mathbb{N} \cup\{0\}$. Thus all the assumptions of Theorem 2.1 hold and $\operatorname{Bpp}(T)$ is nonempty.

Similarly we can prove the following theorems.

Theorem 5.2 Suppose $X, A, A_{0}$, and $B$ are as in Theorem 5.1 and $T: A \rightarrow B$ is a Suzuki type ordered $\Theta$-proximal contraction where we have the assumptions (i)-(v) of Theorem 5.1 . Then $\operatorname{Bpp}(T)$ is nonempty.

Theorem 5.3 Suppose $X, A, A_{0}$, and $B$ are as in Theorem 5.1 and $T: A \rightarrow B$ is an ordered convex proximal contractive mapping of the first type (or the second type) satisfying $T\left(A_{0}\right) \subseteq B_{0}$ and the conditions (ii)-(iv) of Theorem 5.1. Then $\mathrm{Bpp}(T)$ is nonempty. Moreover, $\operatorname{Bpp}(T)$ is singleton if $\alpha(x, y) \geq 0$ for all $x, y \in \operatorname{Bpp}(T)$.

\section{Application to fixed point theory}

Here we deduce certain new and general fixed point results for Suzuki and convex contractions. Our results contain properly the main theorem due to Suzuki [24] and many of its extensions [23] (see also [28]).

If $A=B=X$, then definition (1.2) reduces to the following.

Definition 6.1 A map $T: X \rightarrow X$, is called $\alpha^{+}$-admissible if

$$
\alpha(x, y) \geq 0 \quad \Longrightarrow \quad \alpha(T x, T y) \geq 0
$$

for all $x, y \in X$.

Definition 6.2 A mapping $T: X \rightarrow X$ is called a Suzuki type $\alpha^{+} \psi$-contraction, if

$$
\frac{1}{2} d(x, T x) \leq d(x, y) \quad \Rightarrow \quad \alpha(x, y)+d(T x, T y) \leq \psi(M(x, y))
$$

for all $x, y \in X$. 
Definition 6.3 A mapping $T: X \rightarrow X$ is called a Suzuki type $\alpha^{+} \Theta$-contraction, if

$$
\frac{1}{2} d(x, T x) \leq d(x, y) \quad \Rightarrow \quad \alpha(x, y)+\Theta(d(T x, T y)) \leq[\Theta(M(x, y))]^{k}
$$

for all $x, y \in X, \alpha: X \times X \rightarrow[-\infty, \infty)$ and $\Theta \in \Delta_{\Theta}$.

Now from Theorems 2.1, 2.2 and 3.1, we derive the following new fixed point theorems.

Theorem 6.1 Assume that $X$ is a complete metric space and $T: X \rightarrow X$ is a Suzuki type $\alpha^{+} \psi$-contraction with the following assertions:

(i) $T$ is $\alpha^{+}$-admissible,

(ii) there is $x_{0}$ with $\alpha\left(x_{0}, T x_{0}\right) \geq 0$,

(iii) $T$ is continuous or,

(iv) $X$ is $\alpha$-regular.

Then $F(T)$ is nonempty.

Theorem 6.2 Assume that $X$ is a complete metric space and $T: X \rightarrow X$ is a Suzuki type $\alpha^{+} \Theta$-contraction satisfying the conditions (i)-(iv) in Theorem 6.1. Then $F(T)$ is nonempty.

Theorem 6.3 Suppose $X$ is a complete metric space and $T: X \rightarrow X$ is an $\alpha^{+}$-convex contractive mapping of the first (or the second) type with the following assertions:

(i) $T$ is $\alpha^{+}$-admissible,

(ii) there exists $x_{0}$ such $\alpha\left(x_{0}, T x_{0}\right) \geq 0$,

(iii) $T$ is continuous.

Then $F(T)$ is nonempty.

By taking $\alpha(x, y)=0$ for all $x, y \in X$ in the above theorem, we obtain the main results of Istrățescu [29] as corollaries.

Definition 6.4 A mapping $T: X \rightarrow X$ is called a Suzuki type ordered $\psi$-contraction, if

$$
\frac{1}{2} d(x, T x) \leq d(x, y) \quad \text { and } \quad x \preceq y \quad \Rightarrow \quad d(T x, T y) \leq \psi(M(x, y))
$$

for $x, y \in X, \psi \in \Psi$.

Definition 6.5 A mapping $T: X \rightarrow X$ is called a Suzuki type ordered $\Theta$-contraction, if

$$
\frac{1}{2} d(x, T x) \leq d(x, y) \quad \text { and } \quad x \preceq y \quad \Rightarrow \quad \Theta(d(T x, T y)) \leq[\Theta(M(x, y))]^{k}
$$

for $x, y \in X$ and $\Theta \in \Delta_{\Theta}$.

Theorem 6.4 Suppose $(X, d, \preceq)$ is a complete partially ordered metric space and $T: X \rightarrow$ $X$ is a Suzuki type ordered $\psi$-contraction with the following assertions:

(i) $T$ is an increasing mapping,

(ii) there is $x_{0} \in X$ such that $x_{0} \preceq T x_{0}$,

(iii) $T$ is continuous or,

(iv) $X$ is regular.

Then $F(T)$ is nonempty. 
Theorem 6.5 Suppose $(X, d, \preceq)$ is a complete partially ordered metric space and $T: X \rightarrow$ $X$ is a Suzuki type ordered $\Theta$-contraction satisfying the conditions (i)-(iv) in Theorem 6.4. Then $F(T)$ is nonempty.

Theorem 6.6 Assume that $(X, d, \preceq)$ is a complete partially ordered metric space and $T$ : $X \rightarrow X$ is an ordered convex contractive mapping of the first (or the second) type with the following assertions:

(i) $T$ is increasing,

(ii) there is $x_{0}$ such $x_{0} \preceq T x_{0}$,

(iii) $T$ is continuous.

Then $F(T)$ is singleton.

Remark 6.1 Several more fixed point theorems can be obtained using more choices for function $\Theta$, and/or some other concrete choices of $\alpha$ and $\psi \in \Psi$.

\section{Competing interests}

The authors declare that they have no competing interests.

\section{Authors' contributions}

All authors contributed equally and significantly in writing this article. All authors read and approve the final manuscript.

\section{Author details}

'Department of Mathematics, King Abdulaziz University, P.O. Box 80203, Jeddah, 21589, Saudi Arabia. ${ }^{2}$ Department of Mathematics, Payame Noor University (PNU), P.O. Box 19395-3697, Tehran, Iran. ${ }^{3}$ Young Researchers and Elite Club, Rasht Branch, Islamic Azad University, Rasht, Iran.

\section{Acknowledgements}

This article was funded by the Deanship of Scientific Research (DSR), King Abdulaziz University, Jeddah. Therefore, the authors acknowledge with thanks DSR, KAU for financial support.

Received: 12 August 2015 Accepted: 4 January 2016 Published online: 15 January 2016

\section{References}

1. Amini-Harandi, A, Fakhar, M, Hajisharifi, HR, Hussain, N: Some new results on fixed and best proximity points in preordered metric spaces. Fixed Point Theory Appl. 2013, 263 (2013)

2. Hussain, N, Latif, A, Salimi, P: Best proximity point results for modified Suzuki $\alpha$ - $\psi$-proximal contractions. Fixed Point Theory Appl. 2014, 10 (2014)

3. Hussain, N, Kutbi, MA, Salimi, P: Best proximity point results for modified $\alpha$ - $\psi$-proximal rational contractions. Abstr. Appl. Anal. 2013, Article ID 927457 (2013)

4. Jleli, M, Samet, B: Best proximity points for $\alpha-\psi$-proximal contractive type mappings and applications. Bull. Math. Sci. 137, 977-995 (2013)

5. Jleli, M, Karapinar, E, Samet, B: Best proximity points for generalized $\alpha$ - $\psi$-proximal contractive type mappings. J. Appl. Math. 2013, Article ID 534127 (2013)

6. Latif, A, Hezarjaribi, M, Salimi, P, Hussain, N: Best proximity point theorems for $\alpha$ - $\psi$-proximal contractions in intuitionistic fuzzy metric spaces. J. Inequal. Appl. 2014, 352 (2014)

7. Anuradha, J, Veeramani, P: Proximal pointwise contraction. Topol. Appl. 156(18), 2942-2948 (2009)

8. Sadiq Basha, S, Shahzad, N: Best proximity point theorems for generalized proximal contractions. Fixed Point Theory Appl. 2012, 42 (2012)

9. Di Bari, C, Suzuki, T, Vetro, C: Best proximity points for cyclic Meir-Keeler contractions. Nonlinear Anal. 69(11), 3790-3794 (2008)

10. Eldred, A, Veeramani, PL: Existence and convergence of best proximity points. J. Math. Anal. Appl. 323, 1001-1006 (2006)

11. Eldred, A, Kirk, WA, Veeramani, P: Proximal normal structure and relatively nonexpansive mappings. Stud. Math. 171(3), 283-293 (2005)

12. Kim, WK, Kum, S, Lee, KH: On general best proximity pairs and equilibrium pairs in free abstract economies. Nonlinear Anal. 68(8), 2216-2227 (2008)

13. Kirk, WA, Reich, S, Veeramani, P: Proximal retracts and best proximity pair theorems. Numer. Funct. Anal. Optim. 24, 851-862 (2003)

14. Mongkolkeha, C, Kumam, P: Some common best proximity points for proximity commuting mappings. Optim. Lett. 7, 1825-1836 (2012)

15. Sadiq Basha, S: Extensions of Banach's contraction principle. Numer. Funct. Anal. Optim. 31, 569-576 (2010)

16. Basha, S: Best proximity points: global optimal approximate solution. J. Glob. Optim. 49, 15-21 (2011)

17. Basha, S, Veeramani, P: Best approximations and best proximity pairs. Acta Sci. Math. 63, 289-300 (1997) 
18. Sadiq Basha, S, Veeramani, P: Best proximity point theorem on partially ordered sets. Optim. Lett. 7, 1035-1043 (2012)

19. Samet, B, Vetro, C, Vetro, P: Fixed point theorem for $\alpha-\psi$ contractive type mappings. Nonlinear Anal. 75, 2154-2165 (2012)

20. Sankar Raj, V: A best proximity point theorem for weakly contractive non-self-mappings. Nonlinear Anal. 74(14), 4804-4808 (2011)

21. Sankar Raj, V, Veeramani, P: Best proximity pair theorems for relatively nonexpansive mappings. Appl. Gen. Topol. 10(1), 21-28 (2009)

22. Suzuki, T: The existence of best proximity points with the weak P-property. Fixed Point Theory Appl. 2013, 259 (2013)

23. Suzuki, T: A new type of fixed point theorem in metric spaces. Nonlinear Anal. 71(11), 5313-5317 (2009)

24. Suzuki, T: A generalized Banach contraction principle that characterizes metric completeness. Proc. Am. Math. Soc. 136, 1861-1869 (2008)

25. Suzuki, T, Kikkawa, M, Vetro, C: The existence of best proximity points in metric spaces with the property UC. Nonlinear Anal. 71, 2918-2926 (2009)

26. Zhang, J, Su, Y, Cheng, Q: A note on 'A best proximity point theorem for Geraghty-contractions'. Fixed Point Theory Appl. 2013, 99 (2013)

27. Jleli, M, Samet, B: A new generalization of the Banach contraction principle. J. Inequal. Appl. 2014, 38 (2014)

28. Hussain, N, Salimi, P, Vetro, P: Fixed points for Suzuki- $\varphi-\psi$-contractions with applications to integral equations. Carpath. J. Math. 30(2), 197-207 (2014)

29. Istrăţescu, Vl: Some fixed point theorems for convex contraction mappings and mappings with convex diminishing diameters. I. Ann. Math. Pures Appl. 130, 89-104 (1982)

30. Hussain, N, Kutbi, MA, Khaleghizadeh, S, Salimi, P: Discussions on recent results for $\alpha$ - $\psi$-contractive mappings. Abstr. Appl. Anal. 2014, Article ID 456482 (2014)

31. Gabeleh, M: Best proximity point theorems via proximal non-self mappings. J. Optim. Theory Appl. 164(2), 565-576 (2015)

\section{Submit your manuscript to a SpringerOpen ${ }^{\circ}$ journal and benefit from:}

- Convenient online submission

Rigorous peer review

- Immediate publication on acceptance

- Open access: articles freely available online

- High visibility within the field

- Retaining the copyright to your article 